\section{Interaction of von Willebrand Factor with Human Platelets in the Plasma Milieu}

John Schullek, Jean Jordan, and Robert R. Montgomery The Blood Center of Southeastern Wisconsin and the Department of Pediatrics, The Medical College of Wisconsin, Milwaukee, Wisconsin 53233
4 (vWf) to stimulated platelets in the plasma milieu was performed using a radiolabeled monoclonal antibody to vWf. Plasma proteins specifically inhibited the thrombinand ADP/epinephrine-induced vWf binding to activated platelets but did not inhibit the ristocetin-induced $\mathrm{vWf}$ binding. When normal plasma was heat defibrinated, monoclonal-labeled vWf was bound to platelets following thrombin or ADP/epinephrine stimulation. Furthermore, monoclonal-labeled vWf from afibrinogenemic plasma bound normally to platelets. The binding of $\mathrm{vWf}$ to stimulated platelets in either heat-defibrinated normal plasma or afibrinogenemic plasma was specifically inhibited by the addition of normal plasma fibrinogen in a concentration-dependent manner. At levels of fibrinogen $<1$ $\mathrm{mg} / \mathrm{ml}$, however, vWf binding could be demonstrated. The inhibition by fibrinogen of vWf binding to platelets was competitive and overcome by increased concentrations of vWf. These studies show that thrombin-induced and $\mathrm{ADP} /$ epinephrine-induced $\mathrm{vWf}$ binding to platelets does not occur in the plasma milieu, although at reduced levels of fibrinogen, vWf binding to stimulated platelets can be demonstrated.

\section{Introduction}

The Factor VIII molecular complex is comprised of two proteins-von Willebrand factor (vWf) ${ }^{1}$ and antihemophilic Factor

Dr. R. R. Montgomery is an Established Investigator of the American Heart Association (82-192). Address reprint requests to Dr. Montgomery, The Blood Center of Southeastern Wisconsin, 1701 W. Wisconsin Ave., Milwaukee, WI 53233. 1983.

Received for publication 20 June 1983 and in revised form 11 October

1. Abbreviations used in this paper: AP-1, monoclonal antibody to GPIb; AP-2, monoclonal antibody to the complex of GPIIb/IIIa; AVW-1 and AVW-2, monoclonal antibodies to vWf; GP, glycoprotein; HDNP, heatdefibrinated normal plasma; PAGE, polyacrylamide gel electrophoresis; $\mathrm{vWf}$, von Willebrand factor.

J. Clin. Invest.

(c) The American Society for Clinical Investigation, Inc. 0021-9738/84/02/0421/08 $\$ 1.00$

Volume 73, February 1984, 421-428
(VIII C) $(1,2)$. The vWf portion of the molecule is necessary for the adhesion of normal platelets to damaged endothelium, and it is defective or deficient in von Willebrand's disease (1-3).

The vWf activity is most commonly measured in vitro by its ability to support ristocetin-induced agglutination of formalinfixed platelets; the in vivo stimulus for this reaction, however, is unknown (1-5). Recent studies have demonstrated the binding of ${ }^{125} \mathrm{I}-\mathrm{vWf}$ to washed platelets by thrombin or ADP, thereby suggesting that these might be the physiologic stimuli for $\mathrm{vWf}$ binding in vivo (6-9). Although there was general agreement that ristocetin-induced $\mathrm{vWf}$ binding was to platelet membrane glycoprotein Ib (GPIb) (10-12), studies on the platelets from patients with Glanzmann's thrombasthenia and Bernard-Soulier syndrome suggested that thrombin- and ADP/epinephrine-induced vWf binding were mediated through GPIIb/IIIa $(8,9)$. Furthermore, monoclonal antibodies (AP-1 and AP-2) to these GP (13) blocked the respective vWf binding induced by ristocetin (GPIb) or thrombin and ADP/epinephrine (GPIIb/IIIa) $(9,13)$. These studies (6-9) utilized purified, radiolabeled vWf with washed platelets and were not undertaken in the plasma milieu. The preparations of vWf were shown to have all sizes of multimers (9), but since they were obtained by column chromatography from the void volume fractions, the preparations might not have included all the normal plasma vWf multimers.

To study the binding of plasma vWf to platelets in the presence of normal plasma proteins, we developed a method that enabled us to label the vWf in normal plasma using a radiolabeled monoclonal antibody to the vWf protein. This monoclonal antibody did not inhibit the binding of vWf to platelets by ristocetin, thrombin, or ADP/epinephrine, and identified all multimers of $\mathrm{vWf}$. We were thereby able to measure the binding of $\mathrm{vWf}$ to platelets in the presence of normal plasma without the necessity of purifying the Factor VIII molecular complex. Since this monoclonal antibody was specific for $\mathrm{vWf}$, trace labeling of fibrinogen or other plasma proteins that might contaminate purified vWf could be avoided.

\section{Methods}

Materials. Ristocetin sulfate (H. Lundbeck and Co., Copenhagen, Denmark); apyrase, hirudin, and bovine fraction $\mathrm{V}$ albumin (Sigma Chemical Co., St. Louis, MO); lyophilized fixed platelets (Bio/Data Corp., Horsham, 
PA); Sephadex G50, protein A-Sepharose 4B (Pharmacia Fine Chemicals, Piscataway, NJ); $\mathrm{Na}^{125}$ ( New England Nuclear, Boston, MA); all acrylamide gel electrophoresis reagents and BioGel A15 (Bio-Rad Laboratories, Richmond, CA). Factor VIII concentrate was obtained from Hyland Laboratories, Glendale, CA. Monospecific immunopurified rabbit antibody to mouse IgG was obtained from Zymed Laboratories, Burlingame, CA, and purified human $\alpha$-thrombin was obtained from Dr. David Aronson, Bureau of Biologics, Bethesda, MD. All other reagents were purchased from Sigma Chemical Co. and were analytical grade or the best grade available.

Production of monoclonal antibody to vWf. Commercial Factor VIII concentrate was subjected to molecular exclusion chromatography through $4 \%$ agarose. The void volume fractions containing the vWf protein $(200-400 \mu \mathrm{g} / \mathrm{ml})$ were pooled and used to immunize BALB/c mice by primary intraperitoneal immunization with $0.5 \mathrm{ml}$ of Freund's complete adjuvant. Three subsequent intraperitoneal immunizations were given at 2-wk intervals followed by an intravenous immunization $4 \mathrm{~d}$ before hybridization. Fusion of the immune spleen cells with P3X63Ag8653 myeloma cells was carried out as previously described (13). Positive hybrids were selected using a method of rocket inhibition of $\mathrm{vWf}$ antigen. This technique was modified from a method previously developed to detect the elution of polyspecific antibodies from a vWf immunoaffinity column (14). Since monoclonal antibodies are usually nonprecipitating, the samples consisted of normal plasma and hybridoma spent media that were incubated for $30 \mathrm{~min}$ at room temperature and then incubated with $10 \mu \mathrm{g}$ of rabbit anti-mouse IgG, which caused the precipitating reaction. Quantitative electrophoresis was carried out against ${ }^{125}$ I-labeled polyspecific antibody to vWf. Positive hybrids were demonstrated by inhibition of the vWf rockets (Fig. 1). This method was utilized because we were concerned about the potential alteration of antigenic specificity of purified vWf. Alternatively, an enzyme-linked immunosorbant assay was performed as previously described, except that $\mathrm{vWf}$ was the immobilized antigen (13). Positive hybrids were cloned and recloned by limiting cell dilution and ascites tumors established (13). Two monoclonal antibodies were characterized and termed AVW1 and AVW-2.

Purification and radiolabeling of monoclonal antibody. Monoclonal antibody was purified from ascites fluid by affinity chromatography with protein A-Sepharose 4B, as previously described (13). These preparations were $>95 \%$ homogeneous IgG by sodium dodecyl sulfate-polyacrylamide gel electrophoresis (SDS-PAGE).

Radiolabeling of the monoclonal antibody with ${ }^{125}$ I was done with the chloramine-T method (15). The labeled IgG was separated from the unbound ${ }^{125}$ I using a Sephadex G50 column. The purified, labeled IgG was then kept at $4^{\circ} \mathrm{C}$ in $10 \mathrm{mg} / \mathrm{ml}$ bovine serum albumin. The specific activity of this labeled IgG was $1-5 \times 10^{9} \mathrm{cpm} / \mathrm{mg}$ of IgG.

Preparation of albumin density gradient washed platelets. Plateletrich plasma was obtained from normal donors, a patient with severe von Willebrand's disease ( $<0.001 \mathrm{U} / \mathrm{dl} \mathrm{vWf}$ antigen), and a patient with severe afibrinogenemia. Platelets were washed free of plasma constituents by sequential albumin density gradient centrifugations (16). The platelets were resuspended in divalent cation-free Tyrode's buffer containing 10 $\mathrm{mM}$ Hepes, $\mathrm{pH} 7.35$, and $20 \mathrm{mg} / \mathrm{ml}$ albumin. Platelets were counted in a Coulter ZBI counter (Coulter Electronics, Inc., Hialeah, FL) and adjusted to $2 \times 10^{8}$ platelets $/ \mathrm{ml}$. All experiments were performed in the above buffer alone, or the washed platelets diluted 1:2 with plasma or heat-defibrinated plasma.

Radiolabeling of $v W f$ in intact plasma or heat-defibrinated normal plasma. To avoid the potential selective removal of specific multimers of $\mathrm{vWf}$ by the purification of $\mathrm{vWf}$, we developed a method in which we radiolabeled the $\mathrm{vWf}$ using radiolabeled AVW-1 monoclonal antibody to $\mathrm{vWf}$. Plasma vWf was labeled by adding $0.001-0.01 \mu \mathrm{g}$ of radiolabeled AVW-1 (specific activity $1-5 \times 10^{6} \mathrm{cpm} / \mu \mathrm{g}$ ) to $1.0 \mathrm{ml}$ of pooled normal plasma and incubated at room temperature for $60 \mathrm{~min}$. This monoclonal antibody was specific for $\mathrm{vWf}$ and has been shown not to inhibit the binding of purified $\mathrm{vWf}$ to platelets by thrombin, ADP/epinephrine, or ristocetin. By adding this radiolabeled monoclonal antibody in subsaturating amounts, the plasma vWf was specifically labeled and its binding to platelets could be studied in the presence of plasma. Once plasma vWf was labeled in this manner, 1,000-fold excess of unlabeled monoclonal AVW-1 could not displace the radioactivity from the vWf. Thus, the radioactive antibody could not come off the plasma vWf when exposed to platelets, which could release their own endogenous vWf and bind the AVW-1, if the AVW-1 was not bound to plasma vWf.

Studies on vWf binding in the absence of fibrinogen were carried out either with the plasma from a patient with severe afibrinogenemia (arrangement for plasma and platelet pheresis of this patient in Milwaukee was assisted by Dr. Harold R. Roberts, Chapel Hill, NC) or by heatdefibrinating normal plasma. Plasma was placed at $56^{\circ} \mathrm{C}$ for $10 \mathrm{~min}$ and then centrifuged at $11,000 \mathrm{~g}$ for $10 \mathrm{~min}$ to remove the precipitated fibrinogen. This plasma contained $<0.3 \mathrm{mg} / \mathrm{ml}$ of residual fibrinogen and will be referred to as heat-defibrinated normal plasma (HDNP). The vWf activity of the HDNP was $>98 \%$ of normal when measured in a ristocetin cofactor assay, and equivalent quaritities of ${ }^{125} \mathrm{I}-\mathrm{AVW}-1$ $\mathrm{vWf}$ were bound to platelets by ristocetin when either normal plasma or HDNP was radiolabeled by monoclonal antibody as described above.

Binding assay of ${ }^{125} I-A V W-1-v W f$ to platelets. Platelet-binding experiments were performed by mixing $200 \mu \mathrm{l}$ of AVW-1-labeled normal plasma or HDNP and $200 \mu \mathrm{l}$ of albumin density gradient washed platelets $\left(2 \times 10^{8} / \mathrm{ml}\right)$. The samples were incubated at room temperature for 40 min without agitation following the addition of agonist. For maximal binding of labeled $\mathrm{vWf}$, the following concentrations of agonists were used: ristocetin sulfate, $1.5 \mathrm{mg} / \mathrm{ml}$; ADP/epinephrine, $20 \mu \mathrm{M} / 20 \mathrm{M}$; and human $\alpha$-thrombin, $0.5 \mathrm{U} / \mathrm{ml}$. The platelet-bound $\mathrm{vWf}$ was separated from the unbound supernatant vWf by centrifugation at $11,000 \mathrm{~g}$ for, $3 \mathrm{~min}$ in a fixed angle microcentrifuge (Eppendorf model 5412, Brinkmann Instruments, Inc., Westbury, NY). Since this was a fixed angle centrifuge, the small platelet pellet was on the side of the bottom of the microcentrifuge tube. This permitted complete aspiration of the fluid by placing the tip of the pipette down at the bottom of the tube. The supernate was carefully aspirated, and the remaining tip of the microcentrifuge tube containing the platelets was cut off. Both the supernate and the pellet were counted for ${ }^{125} \mathrm{I}$ radioactivity in a gamma counter (Packard Instrument Co., Inc., Downers Grove, IL). All individual experiments were performed in duplicate and the results averaged. Controls included the same reactants, omitting the addition of the agonist. Typically the background ${ }^{125} \mathrm{I}-\mathrm{vWf}$ binding to platelets was $0.8-2.0 \%$ of the total radioactivity added.

In experiments where binding of $\mathrm{vWf}$ to thrombin-stimulated platelets was performed in the presence of fibrinogen, hirudin $(1 \mathrm{U} / \mathrm{ml})$ was added 5 min following the thrombin activation of platelets and before the addition of plasma or fibrinogen. This inactivated the residual thrombin and prevented clotting.

Inhibition of $v W$ f binding by monoclonal antibodies to platelet membrane GPIb or GPIIb/IIIa. In some experiments, either AP-1 or AP$2(9,13,18)\left(10-50 \mu \mathrm{g} / 10^{8}\right.$ platelets) was added to specifically block GPIb or GPIIb/IIIa, respectively. These monoclonal antibodies were preincubated with the platelets at room temperature for $60 \mathrm{~min}$ before the addition of agonist. Neither of these monoclonal antibodies inhibited the thrombin-induced release of platelet $\mathrm{vWf}$ or platelet factor 4 , although 
AP-2 blocked the rebinding of the endogenous platelet vWf to these platelets, resulting in greater recovery of $\mathrm{vWf}$ in the supernate. Thus, they inhibited receptor interaction with $\mathrm{vWf}$ rather than inhibition of thrombin binding itself.

Effect of $A V W-1$ on the binding of labeled purified $v W f$ to platelets. To substantiate the observation that excess AVW-1 did not inhibit thrombin-induced binding of vWf to platelets, vWf was purified from cryoprecipitate as previously described (17) and concentrated to 750 $\mu \mathrm{g} / \mathrm{ml}$ in dialysis tubing using Sephadex G50. This vWf was radiolabeled with ${ }^{125} \mathrm{I}$ (sp act $25 \times 10^{3} \mathrm{cpm} / \mu \mathrm{g}$ ), as previously described (9). Thrombininduced binding of this radiolabeled vWf $(20 \mu \mathrm{g} / \mathrm{ml})$ was performed in the presence of $0-200 \mu \mathrm{g} / \mathrm{ml}$ of AVW-1 and the percent inhibition of vWf binding was determined.

Quantitation of $v W f$. The amount of $\mathrm{vWf}$ was measured by quantitative immunoelectrophoresis as previously described (14). By staining, $3 \mathrm{U} / \mathrm{dl}$ of vWf could be detected, but by autoradiography as little as $0.001 \mathrm{U} / \mathrm{dl}$ could be measured.

Inhibition of thrombin-induced $v W f$ binding to platelets by fibrinogen. Purified human fibrinogen was the generous gift of Dr. M. W. Mosesson and Dr. D. L. Amrani, Mt. Sinai Medical Center, Milwaukee, WI. It was homogeneous by SDS-PAGE and contained $<0.001 \mathrm{U} / \mathrm{ml}$ of $\mathrm{vWf}$. Fibrinogen was added back to heat-defibrinated normal plasma or to afibrinogenemic plasma at various dilutions to determine the effect on thrombin-induced and ristocetin-induced vWf binding. In the thrombin experiments, hirudin was added as described above.

Competition between $v W f$ and fibrinogen for thrombin-induced platelet binding. To determine whether there was competition between $\mathrm{vWf}$ and fibrinogen, purified vWf $(750 \mu \mathrm{g} / \mathrm{ml})$ was labeled with radiolabeled AVW1. Purified $\mathrm{vWf}$ had to be used so that high concentrations of $\mathrm{vWf}$ could be added. Since $800 \mu \mathrm{g} / \mathrm{ml}$ of fibrinogen was found to inhibit $\sim 50 \%$ of normal vWf binding, increasing concentrations of vWf (50-650 $\mu \mathrm{g}$ ) $\mathrm{ml}$ ) were added to determine whether this inhibition could be overcome.

\section{Results}

Monoclonal antibody to $v W f$. Two monoclonal antibodies to vWf were developed. Positive hybrids were detected with the method of rocket inhibition, as demonstrated in Fig. 1. With this method the screening antigen is normal plasma rather than a purified protein. This avoids possible antigenic restriction imposed by the purification by gel filtration of an antigen like vWf that has a marked variation in molecular size.

One of the monoclonal antibodies, termed AVW-1, recognized antigenic determinants on normal vWf, while the second monoclonal antibody, termed AVW-2, recognized antigenic determinants on both normal $\mathrm{vWf}$ and a fragment of $\mathrm{vWf}$ previously identified in commercial Factor VIII concentrate and in the plasma of patients with disseminated intravascular coagulation (14). Although when normal plasma was utilized, both antibodies gave similar results, AVW-1 has been utilized in the subsequent studies.

Binding of $v W f$ to platelets by ristocetin. Normal plasma vWf was labeled with radiolabeled AVW-1 and then added to formalin-fixed platelets or to albumin density gradient washed platelets. With formalin-fixed platelets, maximal binding was achieved with concentrations of ristocetin $>1.5 \mathrm{mg} / \mathrm{ml}$ at which $65-70 \%$ of the plasma vWf was bound to the platelets. When

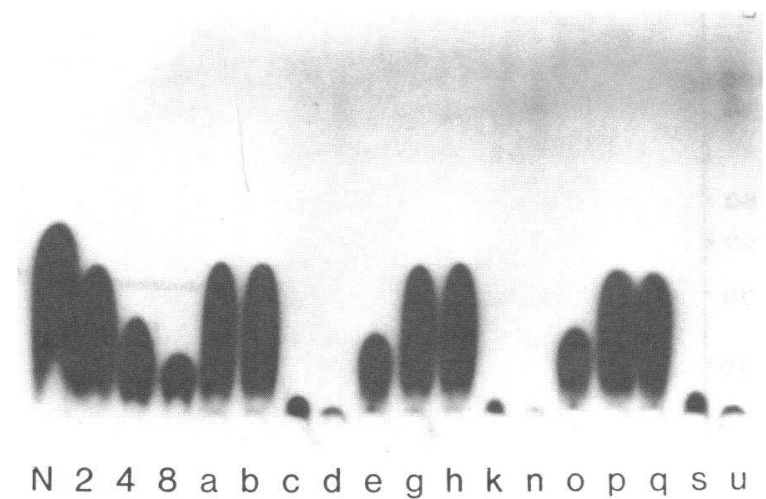

Figure 1. Monoclonal antibodies to $\mathrm{vWf}$ were detected by the inhibition of plasma $v W f$ when studied by quantitative immunoelectrophoresis against radiolabeled polyspecific antibody to vWf; the first four wells contain undiluted and serial twofold dilutions of normal plasma. Normal plasma samples were mixed with samples $(a-u)$ of hybridoma fluid for $30 \mathrm{~min}$, followed by the addition of immunopurified rabbit anti-mouse IgG. Wells $c, d, k, n, s$, and $u$ show almost complete inhibition (i.e., positive for hybridoma antibody), wells $e$ and $o$ show partial inhibition, and wells $a, b, g, h, p$, and $q$ show no inhibition. Note that the screening antigen is unpurified vWf in normal plasma.

von Willebrand's disease plasma was used, the percent binding was essentially background ( $<2 \%$ binding). When this technique was used to study AVW-1-labeled von Willebrand's disease plasma and normal washed platelets, there was no vWf to bind the AVW-1, thereby permitting binding of the monoclonal antibody to any endogenous platelet vWf. If 100 -fold excess of cold AVW-1 was added, however, after the incubation of labeled AVW-1 with the normal plasma, this cold AVW-1 did not compete off the label of the plasma vWf but did prevent the binding of any unbound labeled AVW-1 to the platelet vWf. Heat defibrination did not alter this binding pattern.

Binding of plasma $v W f$ to platelets by thrombin. If thrombininduced binding of vWf was carried out with normal plasma, no binding of vWf could be demonstrated (Fig. 2). However, if the same plasma was initially heat defibrinated, a dose-dependent vWf binding was found. Maximal vWf binding from heat-defibrinated normal plasma was obtained with thrombin doses $>0.1 \mathrm{U} / \mathrm{ml}$. Although ristocetin induced $>65 \% \mathrm{vWf}$ binding, only $25-35 \%$ of plasma vWf was bound to platelets by thrombin. The time course of thrombin binding of $\mathrm{vWf}$ is shown in Fig. 3. Maximal binding was reached at $30-40 \mathrm{~min}$. This is similar to that reported for purified labeled vWf $(6,9)$.

Binding of $v W f$ to von Willebrand platelets. The binding of vWf in heat-defibrinated normal plasma to von Willebrand platelets and normal platelets was identical. Furthermore, no binding of radioactivity was demonstrated when radiolabeled monoclonal antibody AVW-1 was added to heat-defibrinated von Willebrand plasma and tested against von Willebrand platelets using thrombin. 

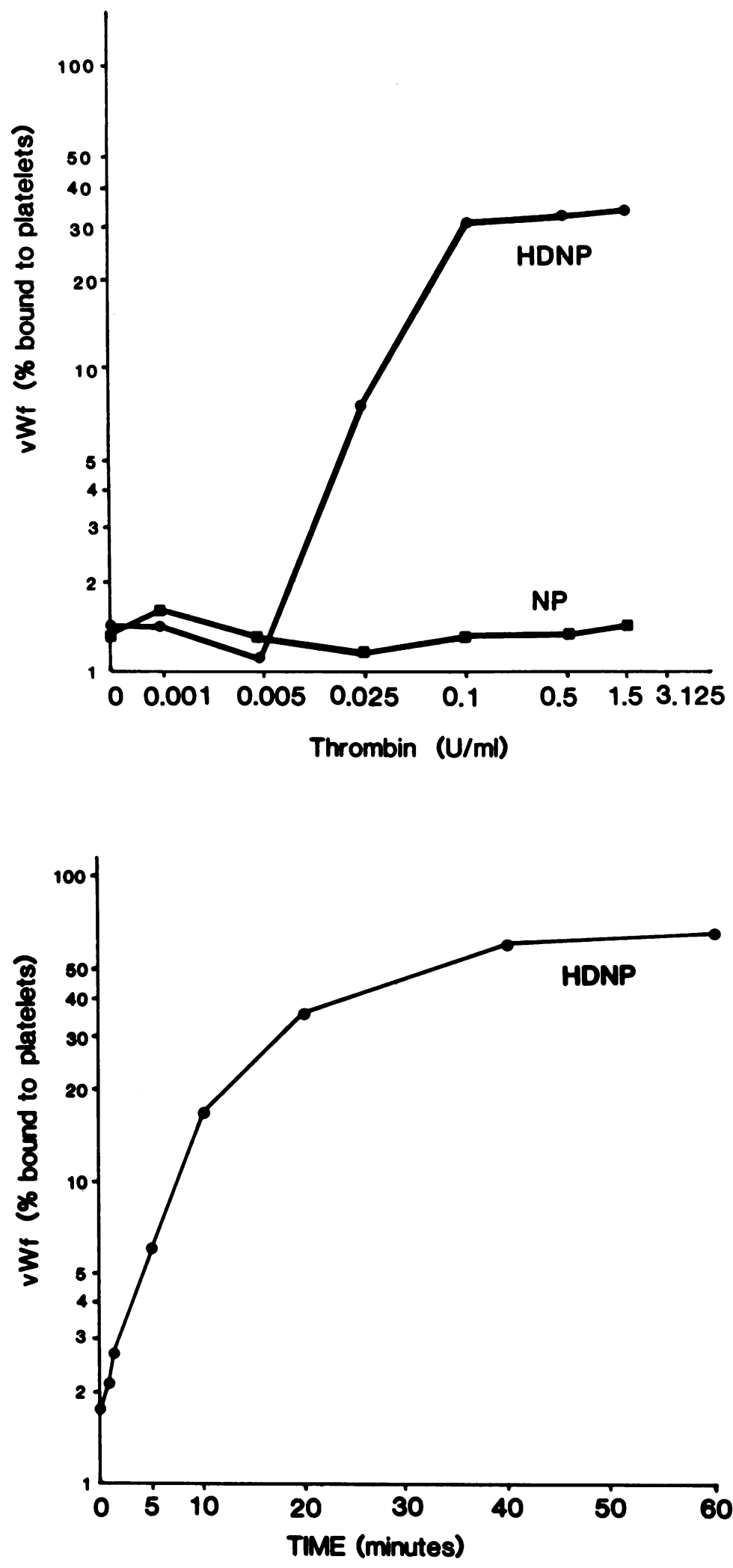

Figure 2. Specific binding of vWf to thrombin-stimulated platelets in the presence of normal plasma (NP) or HDNP. Increasing thrombin concentration induced the binding of vWf to platelets when HDNP was used, but no binding could be demonstrated when normal plasma was used. vWf in plasma was tagged with radiolabeled monoclonal antibody.

Figure 3. Time course of $\mathrm{vWf}$ binding to platelets by $0.5 \mathrm{U} /$ $\mathrm{ml}$ of thrombin. $\mathrm{vWf}$ was tagged with radiolabeled AVW-1 and added to washed normal platelets. Following thrombin stimulation, aliquots were tested at various time intervals for amount of monoclonal-labeled vWf bound to the platelets. Maximal binding was achieved within 30-40 min. 
Fig. 4 shows the specific binding of AVW-1 labeled vWf to von Willebrand's disease platelets, when the platelet pellet was solubilized with Triton X-100 and analyzed by crossed immunoelectrophoresis against nonlabeled anti-vWf antisera. When heat-defibrinated von Willebrand's disease plasma was substituted for HDNP, no radioactive precipitin arc was seen.

Binding of $v W f$ to platelets by ADP/epinephrine. When ADP/ epinephrine-induced $\mathrm{vWf}$ binding was studied, no binding of vWf to platelets could be demonstrated when normal plasma was used. Following heat defibrination, however, 30-40\% of plasma vWf was bound to the platelets-levels similar to those seen with thrombin (Fig. 5). There was more variability in individual platelet responsiveness to ADP/epinephrine than with thrombin, although experiments performed on the same batch of platelets were highly reproducible ( $<10 \%$ variability).

Inhibition of $v$ Wf binding by monoclonal antibodies to GPIb and GPIIb/IIIa. Previous studies on purified vWf binding to platelets demonstrated inhibition of ristocetin-induced vWf binding by AP-1, a monoclonal antibody to GPIb, and inhibition of thrombin-induced vWf by AP-2, a monoclonal antibody to GPIIb/IIIa $(9,18)$. AP-2 blocks the monoclonal-labeled vWf binding to platelets induced by thrombin ( $>92 \%)$ and ADPepinephrine ( $>96 \%$ ) but does not block the ristocetin-induced binding of vWf (Table I). AP-1, however, has little effect on thrombin- or ADP/epinephrine-induced binding but blocks

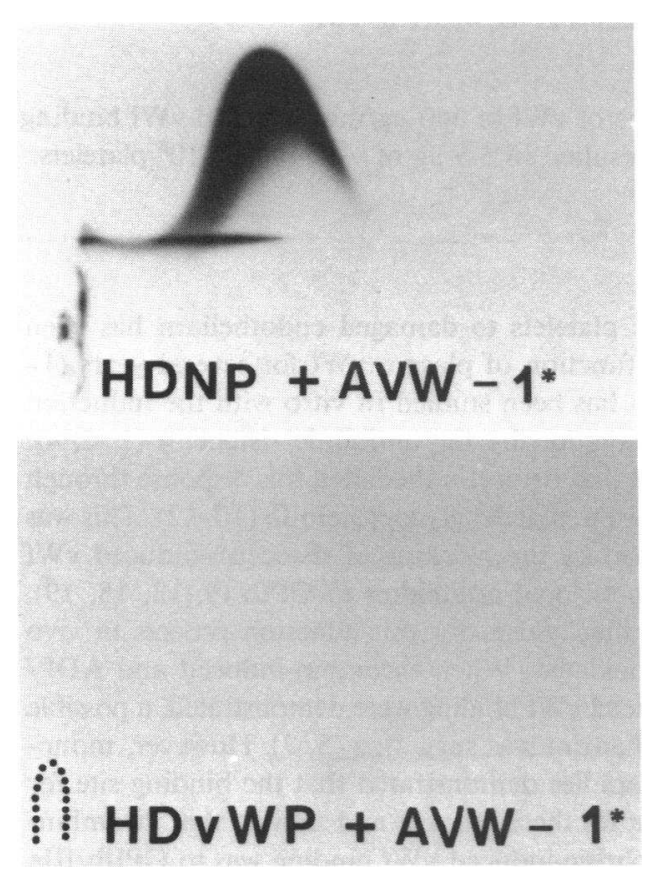

Figure 4. Crossed immunoelectrophoresis of Triton X-100-solubilized sedimented von Willebrand platelets that had been activated by thrombin in the presence of labeled HDNP or von Willebrand plasma. The AVW-1 could be used to evaluate the vWf bound by thrombin to these platelets.

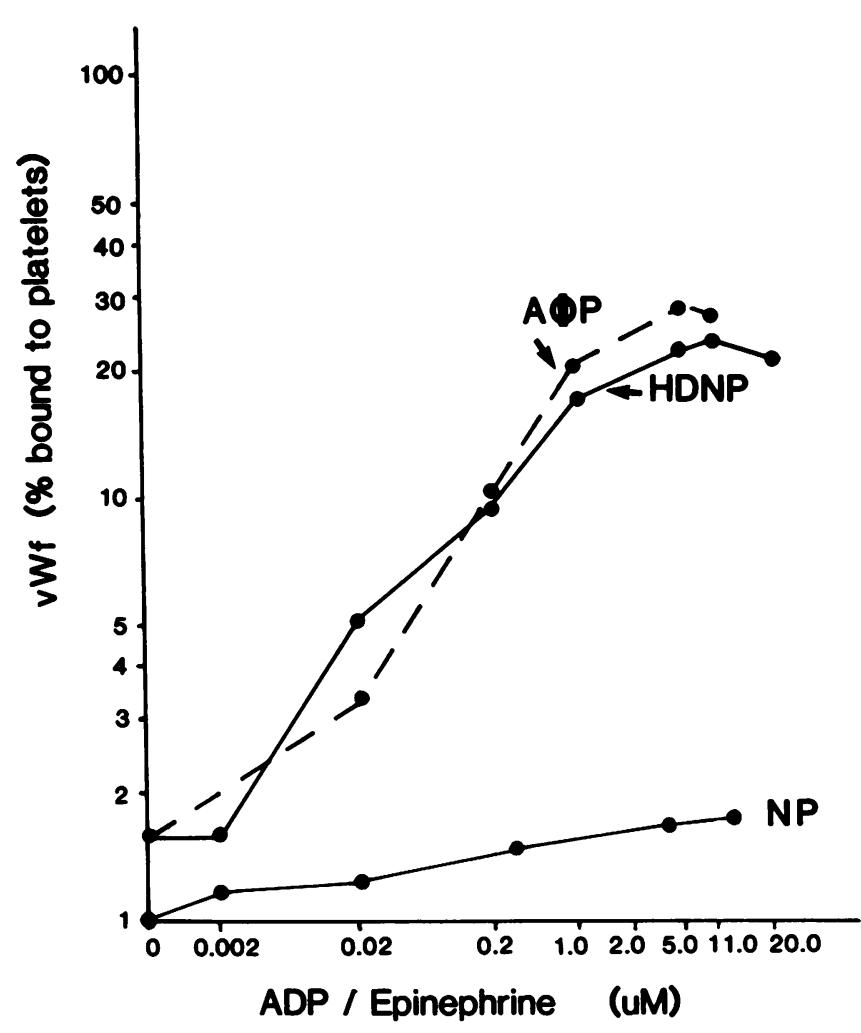

Figure 5. Monoclonal-labeled vWf bound to platelets by ADP and epinephrine in the presence of normal plasma, afibrinogenemic plasma, or HDNP. No binding of vWf was demonstrated in the presence of normal plasma, but $30-40 \%$ of the vWf was bound after initially heat defibrinating the same normal plasma or when afibrinogenemic plasma was substituted as the plasma source of vWf. Maximal binding was achieved at concentrations of $2.0 \mu \mathrm{M}$ ADP and epinephrine.

$>94 \%$ of the ristocetin-induced vWf binding to platelets. These results obtained with monoclonal-labeled vWf are therefore similar to the results obtained when $\mathrm{vWf}$ is labeled $(9,18)$.

Effect of $A V W-1$ on the thrombin-induced binding of radiolabeled purified $v W f$ to platelets. Although the above studies were done on monoclonally labeled plasma vWf, we also tested

Table I. Percent Inhibition of $v W F$ Binding to Washed Platelets by Monoclonal Antibodies to GPIb (AP-1) and GPIIb/IIIa (AP-2)

\begin{tabular}{llcc}
\hline & & \multicolumn{2}{c}{$\begin{array}{c}\text { Inhibition of vWf } \\
\text { binding }\end{array}$} \\
\cline { 3 - 4 } Agonist & Concentration & AP-1 & AP-2 \\
\hline & & $\%$ & $\%$ \\
Thrombin & $0.5 \mathrm{U} / \mathrm{ml}$ & 0 & 93 \\
ADP/epinephrine & $20 \mu \mathrm{M}$ & 6 & 97 \\
Ristocetin & $1.5 \mathrm{mg} / \mathrm{ml}$ & 96 & 4 \\
& & & \\
\hline
\end{tabular}


the effect of excess AVW-1 on thrombin-induced binding of radiolabeled purified vWf. The results given in Table II demonstrate the inhibition of thrombin-induced $\mathrm{vWf}$ binding to platelets by AVW-1. Even a 20,000-fold excess of the AVW-1 used to monoclonally label plasma vWf only reduced the vWf binding by $11 \%$. Thus, the concentration of AVW-1 used to monoclonally label plasma vWf in our experiments did not adversely affect the binding of the vWf. In fact, radiolabeling vWf usually resulted in a $10-20 \%$ decrease in vWf binding compared with monoclonally labeling the same purified $\mathrm{vWf}$ (data not shown).

Binding of $v W f$ to platelets in afibrinogenemic plasma. Since heating of plasma may alter proteins and/or proteases other than fibrinogen, the binding of vWf needed to be studied in hereditary afibrinogenemic plasma. The thrombin-induced vWf binding to afibrinogenemic platelets was similar for heat-defibrinated normal plasma or nonheated afibrinogenemic plasma (Fig. 6). Likewise, ADP/epinephrine-induced vWf binding was similar in these two preparations (Fig. 5). When monoclonallabeled platelet-rich afibrinogenemic plasma and washed afibrinogenemic platelets plus monoclonal-labeled afibrinogenemic plasma were compared, no differences could be demonstrated (data not shown).

Inhibition of thrombin-induced $v$ Wf binding by fibrinogen. To study the direct inhibition of thrombin-induced $\mathrm{vWf}$ binding to platelets, purified fibrinogen was added back to the afibrinogenemic plasma or heat-defibrinated plasma. In these experiments hirudin was added after the thrombin activation of platelets to prevent clotting of the fibrinogen. At physiologic fibrinogen concentrations, $>90 \%$ of the thrombin-induced binding of vWf is inhibited (Fig. 7). This inhibition is dosedependent and is similar in heat-defibrinated normal plasma and afibrinogenemic plasma (data not shown). During intravascular consumption of fibrinogen, levels of fibrinogen commonly drop to $<75 \mathrm{mg} / \mathrm{dl}$. At these concentrations of fibrinogen, thrombin will induce significant vWf binding.

Competition between $v W f$ and fibrinogen for thrombin-induced binding. At a concentration of fibrinogen $(800 \mu \mathrm{g} / \mathrm{ml})$ that inhibits $60 \%$ of the maximal vWf binding induced by thrombin at normal plasma concentrations of $\mathrm{vWf}$, increased levels of vWf overcame this inhibition as shown in Table III.

Table II. Effect of Excess AVW-1 on Thrombin-induced $v W f$ Binding to Platelets

\begin{tabular}{cl}
\hline $\mathrm{AVW}-1$ added & Inhibition of $\mathrm{vWf}$ binding \\
\hline$\mu g / m l$ & $\%$ \\
0 & 0 \\
0.2 & 1 \\
0.3 & 2 \\
1.4 & 5 \\
28 & 10 \\
200 & 11 \\
\hline
\end{tabular}

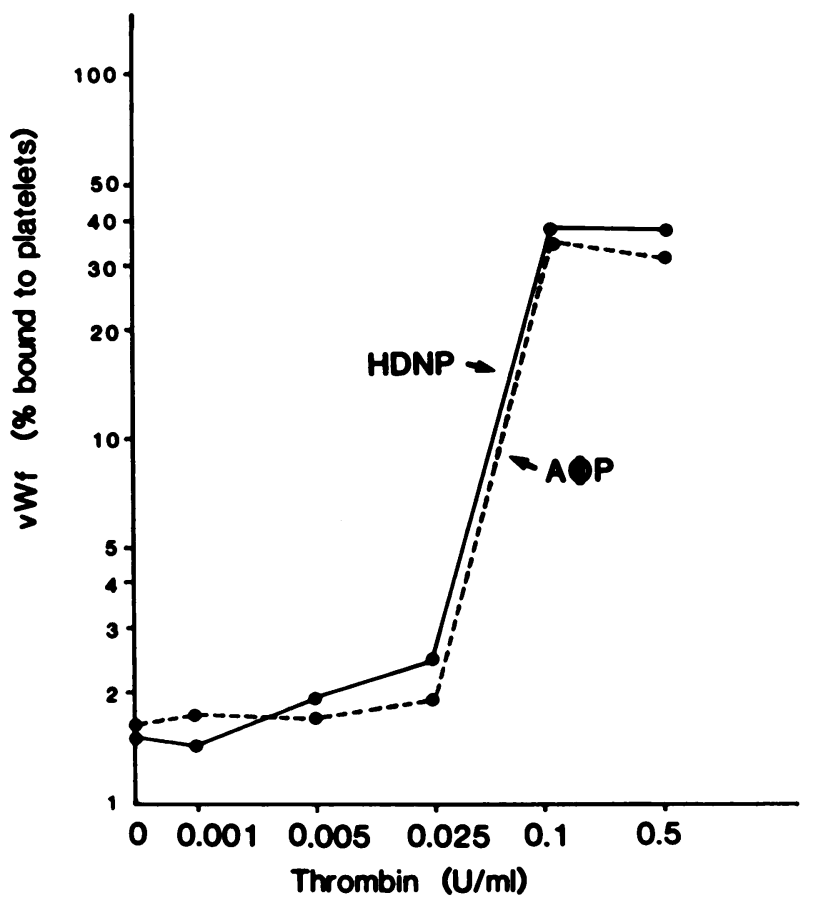

Figure 6. Monoclonal-labeled vWf binding to platelets in response to thrombin. Binding of vWf to platelets occurred when fibrinogen was removed either by heat defibrination of normal plasma or by using afibrinogenemic plasma as the source of vWf.

At concentrations of $\mathrm{vWf}$ of $640 \mu \mathrm{g} / \mathrm{ml}$, maximal $\mathrm{vWf}$ binding occurred. This resulted in $5.5 \mu \mathrm{g}$ of $\mathrm{vWf}$ bound $/ 10^{8}$ platelets.

\section{Discussion}

The adhesion of platelets to damaged endothelium has been recognized as a function of plasma vWf for several years (14). This function has been studied in vitro with the induction of platelet agglutination by the antibiotic ristocetin $(1,2,4)$. Studies suggested that ristocetin mediated this response through the binding of $\mathrm{vWf}$ to platelet glycoprotein $\mathrm{Ib}(10-12)$. This was recently confirmed by the blocking of ristocetin-induced $\mathrm{vWf}$ binding with monoclonal antibodies to GPIb $(9,13,18,19)$. The physiologic mechanism for this adhesion process in vivo has not been elucidated. When thrombin-induced and ADP/ epinephrine-induced $\mathrm{vWf}$ binding were demonstrated, a possible physiologic mechanism was suggested $(5,7)$. However, monoclonal antibody studies demonstrated that the binding site for vWf was different for these agonists and showed that thrombinand ADP/epinephrine-induced vWf binding was to GPIIb/IIIa and not to GPIb (9).

The recent reports demonstrating this thrombin-induced binding of vWf to platelets have used purified $\mathrm{vWf}$ and washed platelets (5, 7-9). Although one report claimed a lack of inhibition of vWf binding by fibrinogen (5), none of the reports 


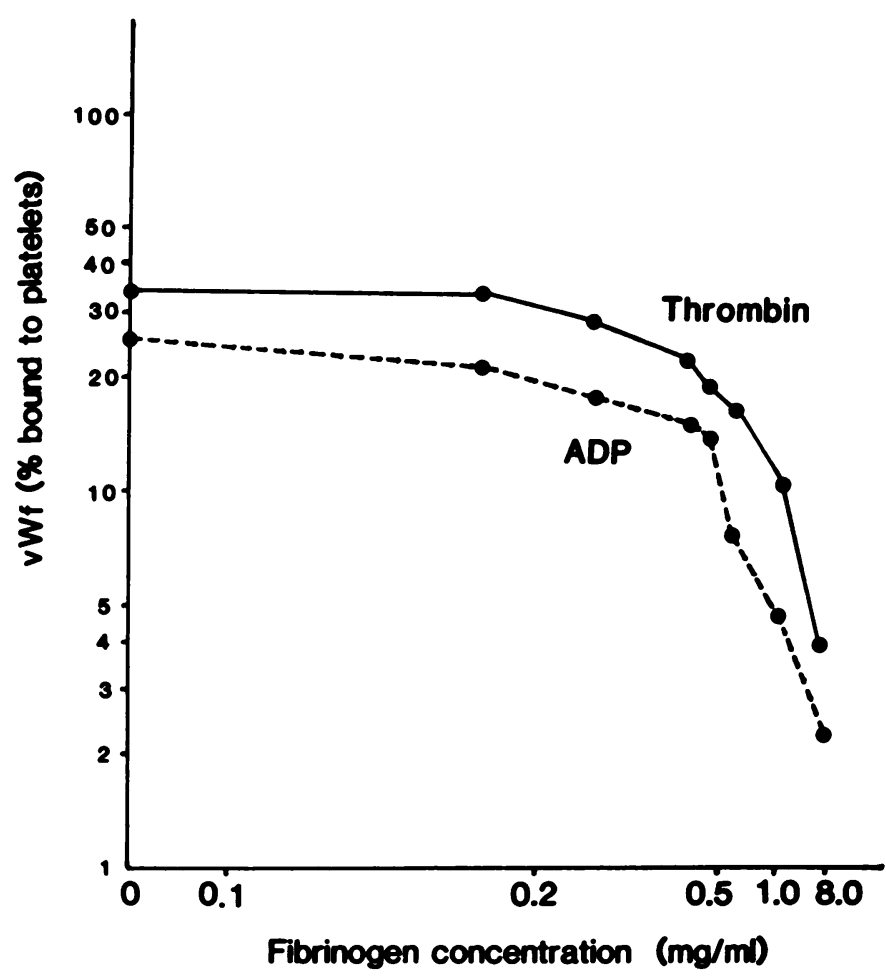

studied this binding in the presence of normal plasma proteins. Furthermore, the binding studies were performed with purified $v W f$. Since most methods for purifying vWf use molecular size as a major step in purification, this may result in the restriction of the size of the multimers separated because of the marked heterogeneity in molecular weight of the plasma vWf multimers. Therefore, a method was needed that would permit the labeling of all the plasma vWf multimers and would permit the binding to be performed in the presence of other plasma proteins. In the process of developing monoclonal antibodies to plasma vWf,

Table III. Competition between $v W f$ and Fibrinogen for Thrombin-induced Binding to Platelets

\begin{tabular}{lcl}
\hline Fibrinogen & $\mathrm{vWf}$ & Inhibition of vWf binding* \\
\hline$\mu g / m l$ & $\mu g / m l$ & $\%$ \\
800 & 50 & 64 \\
800 & 100 & 54 \\
800 & 200 & 58 \\
800 & 320 & 54 \\
800 & 400 & 29 \\
800 & 640 & 0
\end{tabular}

*\% inhibition $=$

vWf binding (no fibrinogen) - vWf binding (fibrinogen) vWf binding (no fibrinogen)
Figure 7. Inhibition of vWf binding to thrombin-stimulated platelets by fibrinogen. Normal plasma was heat defibrinated at $56^{\circ} \mathrm{C}$ and mixed with the radiolabeled monoclonal antibody to $\mathrm{vWf}$. Various concentrations of purified fibrinogen were added. For the ADP binding experiments, these plasma mixtures were added to washed normal platelets and activated with ADP/epinephrine. For the thrombin experiments, washed normal platelets were activated with thrombin and then the free thrombin inactivated with hirudin $1 \mathrm{U} /$ $\mathrm{ml}$. The activated platelets were added to the monoclonal-labeled HDNP and fibrinogen mixtures for $30 \mathrm{~min}$ and the platelet-bound vWf determined. Although at concentrations of fibrinogen $<1 \mathrm{mg} /$ $\mathrm{ml}$, vWf binding did occur, normal plasma concentration of fibrinogen inhibited this binding. two monoclonal antibodies were identified that bound to all multimers of plasma vWf, yet did not inhibit the binding of vWf to platelets by ristocetin, thrombin, or ADP/epinephrine. Preliminary studies with ristocetin-induced binding of vWf suggested that AVW-1 could be radiolabeled and used to tag the plasma vWf. This specifically radiolabeled all of the vWf multimers without the need to purify $v W f$, during which trace amounts of other plasma proteins such as fibrinogen might be copurified and subsequently radiolabeled. Even a 20,000-fold excess of this monoclonal antibody did not significantly reduce the vWf binding induced by thrombin. Most investigators seek monoclonal antibodies with a specificity for inhibition of an activity or mechanism. Our studies, however, demonstrate a specific use for noninhibitory monoclonal antibodies that may be used as tags for following specific proteins in complex physiologic reactions. This method may be used when purification of a protein is difficult or undesirable, as well as when radiolabeling alters a protein's function.

In our studies we demonstrate the inhibition by fibrinogen of the thrombin-induced and ADP-epinephrine-induced binding of $\mathrm{vWf}$ to platelets. Using the method of labeling the specific plasma protein ( $\mathrm{vWf}$ ) with a radiolabeled monoclonal antibody to $\mathrm{vWf}$ permits the study of $\mathrm{vWf}$ binding in the presence of other normal plasma proteins. Our studies fail to show ADPepinephrine- or thrombin-induced $\mathrm{vWf}$ binding in the presence of normal plasma proteins. Modification of the plasma by heating to reduce the amount of fibrinogen resulted in the identification of agonist-induced vWf binding similar to that seen with purified 
vWf and washed platelets. Since heating at $56^{\circ} \mathrm{C}$ might result in the modification of other proteins, we studied $\mathrm{vWf}$ binding in plasma from a patient with severe afibrinogenemia. The vWf binding in HDNP was identical to that seen in afibrinogenemic plasma. In both plasmas, this vWf binding was inhibited by the addition of normal purified human fibrinogen in a concentrationdependent manner.

At physiologic concentrations of fibrinogen, $\mathrm{vWf}$ binding to platelets by either thrombin or ADP/epinephrine does not appear to occur. Thus, these agonists are most likely not stimuli for platelet adhesion in vivo, and $\mathrm{vWf}$ binding may not play a role in platelet aggregation. In patients with afibrinogenemia or with a pathologic decrease in plasma fibrinogen, however, this mechanism may be operational and be an alternative pathway for platelet aggregation and/or adhesion. The inhibition of $\mathrm{vWf}$ binding by moderate levels of fibrinogen may be overcome with excess vWf, thereby suggesting competitive binding.

A method for screening monoclonal antibody without purifying an antigen was also developed. This method permits the detection of hybridoma antibodies to vWf by "rocket inhibition" of normal plasma vWf when quantitative immunoelectrophoresis is carried out against polyspecific rabbit anti-vWf. This method has been applied to the detection of monoclonal antibodies to platelet membrane GP (Kunicki, T. J., and R. R. Montgomery, unpublished observations). This method is particularly helpful when a complex polyspecific antibody is available (i.e., anti-whole platelet antisera) and a crude immunogen is used. Multiple monoclonal antibodies may be detected without purifying each individual protein for individual monoclonal screening. If a precipitating polyspecific antibody is available for a given antigen, even normal plasma may be used as the source for screening antigen.

\section{Acknowledgments}

We wish to thank Dr. Thomas J. Kunicki and Dr. Michael W. Mosesson for their helpful discussions on this project, and Wendy Stinebaugh for her preparation of the manuscript and editorial assistance.

This work was supported by grants HL-28444 and HL-29815 of the National Heart, Lung, and Blood Institute and grant 80-803 of the American Heart Association.

\section{References}

1. Zimmerman, T. S., and Z. M. Ruggeri. 1982. von Willebrand's disease. In Progress in Hemostasis and Thrombosis. T. H. Spaet, editor. Grune \& Stratton, Inc., New York. 6:203-236.

2. Hoyer, L. W. 1981. The Factor VIII complex: structure and function. Blood. 58:1-13.

3. Weiss, H. J., H. R. Baumgartner, T. S. Tschopp, V. T. Turitto, and D. Cohen. 1978. Correction by Factor VIII of the impaired platelet adhesion to subendothelium in von Willebrand's disease. Blood. 51:267279.

4. Howard, M. A., R. J. Sawers, and B. G. Firkin. 1973. Ristocetin: a means of differentiating von Willebrand's disease into two groups. Blood. 41:687-690.

5. Weiss, H. J., J. Rogers, and H. Brand. 1973. Defective ristocetininduced platelet aggregation in von Willebrand's disease and its correction by Factor VIII. J. Clin. Invest. 52:2697-2707.

6. Fujimoto, T., S. Ohara, and J. Hawiger. 1982. Thrombin-induced exposure and prostacyclin inhibition of the receptor for Factor VIII/ von Willebrand factor on human platelets. J. Clin. Invest. 69:12121222.

7. Fujimoto, J., and J. Hawiger. 1982. Adenosine diphosphate induces binding of von Willebrand factor to human platelets. Nature (Lond.). 297:154-156.

8. Ruggeri, Z. M., R. Bader, and L. DeMarco. 1982. Glanzmann's thrombasthenia: deficient binding of von Willebrand factor to thrombinstimulated platelets. Proc. Natl. Acad. Sci. USA. 79:6038-6041.

9. Ruggeri, Z. M., L. DeMarco, L. Gatti, R. Bader, and R. R. Montgomery. 1983. Platelets have more than one binding site for von Willebrand factor. J. Clin. Invest. 72:1-12.

10. Phillips, D. R. 1979. An evaluation of membrane glycoproteins in platelet adhesion and aggregation. In Progress in Thrombosis and Hemostasis. T. H. Spaet, editor. Grune \& Stratton, Inc., New York. 5:81-109.

11. Nurden, A. T., and J. P. Caen. 1979. Different glycoprotein abnormalities in thrombasthenic and Bernard-Soulier platelets. Semin. Hematol. 16:234-250.

12. Jamieson, G. A., T. Okumura, B. Fishback, M. M. Johnson, J. J. Egan, and H. J. Weiss. 1979. Platelet membrane glycoproteins in thrombasthenia, Bernard-Soulier syndrome, and storage pool disease. J. Lab. Clin. Med. 93:652-660.

13. Montgomery, R. R., T. J. Kunicki, D. Pidard, and M. Corcoran. 1983. Diagnosis of Bernard-Soulier syndrome and Glanzmann's thrombasthenia with a monoclonal assay on whole blood. J. Clin. Invest. 71:385-389.

14. Montgomery, R. R., and J. Johnson. 1982. Specific Factor VIIIrelated antigen fragmentation: an in vivo and in vitro phenomenon. Blood. 60:930-939.

15. McConahey, P. J., and F. J. Dixon. 1966. A method of trace iodination of proteins for immunologic studies. Int. Arch. Allergy Appl. Immunol. 29:185-189.

16. Scott, J. P., and R. R. Montgomery. 1981. Platelet von Willebrand's antigen II: active release by aggregating agents and a marker of platelet release reaction in vivo. Blood. 58:1075-1080.

17. Montgomery, R. R., and T. S. Zimmerman. 1978. von Willebrand's disease antigen II-a new plasma and platelet antigen deficient in severe von Willebrand's disease. J. Clin. Invest. 61:1498-1507.

18. Pidard, D., R. R. Montgomery, J. S. Bennett, and T. J. Kunicki. 1983. Interaction of AP-2, a monoclonal antibody specific for the human platelet glycoprotein IIb-IIla complex, with intact platelets. J. Biol. Chem. 258:12582-12586.

19. Coller, B. S., E. I. Peerschke, L. E. Scudder, and C. A. Sullivan. 1983. Studies with a murine monoclonal antibody that abolishes ristocetin-induced binding of von Willebrand factor to platelets: additional evidence in support of GPIb as a platelet receptor for von Willebrand factor. Blood. 61:99-110. 